\title{
Effects of Diabetes Education on Emotional Distress in Patients with Type 2 Diabetes- An Experimental Study
}

\author{
Alida Ramaj1, Fatjona Kamberi², Johann Behrens ${ }^{3}$ \\ ${ }^{1}$ Universitätsklinikum (AöR) Gesundheits- und Kranken-/Kinderkrankenpflegeschule, Köln, Germany \\ ${ }^{2}$ Research Center of Public Health, Faculty of Public Health, University of Vlore "Ismail Qemali”, Vlore, Albania \\ ${ }^{3}$ Martin-Luther-Universität Halle-Wittenberg * Medizinische Fakultät, Institut für Gesundheits- und Pflegewissenschaft, \\ Halle/Saale, Germany \\ Email: alidaramaj35@gmail.com,fatjonakamberi@gmail.com
}

How to cite this paper: Ramaj, A., Kamberi, F. and Behrens, J. (2019) Effects of Diabetes Education on Emotional Distress in Patients with Type 2 Diabetes-An Experimental Study. Open Journal of Endocrine and Metabolic Diseases, 9, 9-20. https://doi.org/10.4236/ojemd.2019.92002

Received: January 31, 2019

Accepted: February 15, 2019

Published: February 18, 2019

Copyright (c) 2019 by author(s) and Scientific Research Publishing Inc. This work is licensed under the Creative Commons Attribution International License (CC BY 4.0).

http://creativecommons.org/licenses/by/4.0/

\begin{abstract}
Objective: It was to evaluate the effect of diabetes education on emotional distress in type 2 diabetes patients treated with oral medications. Methods: The experimental study took place in Albania and overall, 200 type 2 diabetes patients were enrolled (in both groups, intervention, and control) treated with oral medications, having levels of Glycated hemoglobin HbAlc $>6.5 \%$ as well the absence of associated diseases such as dementia and psychiatric disorders. Patients were randomly selected from the medical registry of family physicians in the Tirana region. Patients were screened for the emotional distress before and after the intervention with the self-administered questionnaire Problem Areas in Diabetes PAID 5. In addition, the levels of $\mathrm{HbAlc}$ in \% were evaluated before and after intervention in both groups. Only intervention group underwent four diabetes education sessions offered by trained nursing staff while the control group continued the previous regime. The questionnaire reliability analysis was estimated by the Cronbach alpha coefficient. To compare the groups the t-test was used and the value of $\mathrm{p}<0.05$ was considered significant. Results: Mean age of patients in intervention and control group was respectively $54.03 \pm 9.57$ and $55.82 \pm 7.86$. Before and after health education PAID 5 scores for the intervention group were respectively 11.3 vs. 8.75 while for the control group 11.9 vs. $11.35, \mathrm{p}=0.018$. Levels of $\mathrm{HbA} 1 \mathrm{c} \%$ before and after education for the intervention group were $7.02 \mathrm{vs}$. 6.2 while for the control group 6.9 vs. $6.8, p=0.001$. Positive and significant correlation $(r=0.321, p=0.001)$ was between level of emotional distress and the age of the patients. Conclusions: The study found that besides better control of diabetes, additional education of diabetic patients seemed to sig-
\end{abstract}


nificantly improve the level of emotional distress due to diabetes in diabetic patients.

Keywords

Emotional Distress, Type 2 Diabetes, Health Education, PAID 5, Experimental Study

\section{Introduction}

Globally, the number of adult people living with type 2 diabetes is increased significantly and is a reflection of increased risk factors and poor management of the disease [1]. Type 2 diabetes is a chronic disease characterized by elevated levels of blood glucose referred differently as non-insulin-dependent diabetes [2]. A study carried out in Tirana, Albania in 2012 found that the prevalence of diabetes was $11.5 \%$ and higher among lower educated adults compared to young people [3]. People first diagnosed with diabetes experience psychological changes as anger, emotional distress and depression [4]. Diabetes distress is a negative emotion faced by persons who are diagnosed with diabetes related to glycemic control [5]. Diabetes distress is an emotional response to the life-changing related to diabetes. It is distinct from depression and is a product of emotional adjustment that a person with diabetes experiences. In addition, diabetes distress has been found to be significantly associated with Glycated hemoglobin $\left(\mathrm{HbA}_{\mathrm{cc}}\right)$ level and with the adoption of self-care behaviors [6]. Also, a study found that psychological distress improved the onset of diabetes in people with advanced pre-diabetes [7]. In addition, a longitudinal study found that emotional stress, anxiety and sleeping problems increased the risk for type 2 diabetes [8]. A study which included insulin and oral- or diet-treated patients found that patients treated with insulin reported higher emotional distress. Also, the same study emphasized addressing emotional distress by health professionals as a factor influencing the quality of life of people with diabetes [9]. Health education in diabetic patients has been associated with better glycemic control and prevention of complications related [10]. In addition, addressing emotional distress in diabetic patients during assessment and intervention in clinical practice provides glycemic control through the orientation of the patient toward self-management behaviors [11]. A quasi-experimental study showed that health education in diabetic patients played a key role in diabetes management and related problems [12], while another study showed that health education of diabetic patients had an impact on psychological well-being and quality of life [13].

\section{Materials and Methods}

The purpose of the experimental study was to evaluate the impact of the education program at the level of emotional distress associated with diabetes as well as the link between the education program age, patient gender, and emotional distress. 


\subsection{Study Population}

The study took place in Albania during March to August 2016 and included 20 residential areas in the Tirana region where family physicians provide services. These 20 physicians and therefore diabetic patients were randomly selected from the Register of Compulsory Medical Insurance Funds (as the institution responsible for concluding work contracts with family practitioners) [14] [15] for the Tirana region. For each of the selected physicians, at least 10 patients who meet the inclusion criteria in the study were selected. Inclusion criteria: diabetes type 2 patients who are treated with oral medications; have a level of $\mathrm{HbAlc}>6.5 \%$; agree to participate in the study. Exclusion criteria: the presence of associated diseases such as dementia and psychiatric disorders; disagree to participate in the study. The study population was in total 200 patients in both groups (control and intervention). Patients were divided as control or intervention group based on according to the following rule. In one box were placed twenty numbers that corresponded to the number of physicians selected and who had expressed readiness to take part in the study. Each physician was asked to take a number and each number corresponded to ten patients at that physician. The first-choice physician's patients were clustered in the intervention group while the second-choice physician's patients clustered to the control group. This procedure was followed until 20 numbers were selected. During the selection, none of the physicians, patients or laboratory personnel who analyzed the values of HbAlc were unaware of which group the patients were in. The study was conducted in accordance with the requirements of the National Statement on Ethical Conduct in Human Research with study protocol approved date March 2016 by the Medical Ethics Committee, University of Medicine, Tirana, Albania. Patients were assured anonymity and each of them gave consent for participation in the study after fully informed about the purpose of the study.

\subsection{Data Collection Instrument}

The data was collected through the self-administered PAID 5 questionnaire, which is an abbreviated version of the PAID questionnaire. Problem Areas in Diabetes Questionnaire (PAID) is a tool that it was developed to identify the patient's emotional distress. The PAID measure of diabetes-related emotional distress correlates with measures of depression, social support, health beliefs, and coping style, as well as predicts future blood glucose control of the patient. It is found that the questionnaire has a high degree of sensitivity to detect changes as a result of educational health interventions [16]. PAID 5 questionnaire the short version of PAID includes five questions that measure the emotional distress of diabetic patients. For each answer is the possibility to respond with five alternatives; not a problem $=0$; minor problem $=1$; moderate problem $=2$; somewhat serious problem $=3$; serious problem $=4$. In the PAID 5 questionnaire, a total score of $\geq 8$ indicates possible diabetes-related emotional distress [17]. Studies have found that the PAID 5 has satisfactory sensitivity and specificity when is 
used to identify emotional distress related to diabetes [18]. In addition, a study found that the questionnaire PAID 5 is best handled practically than the full form of PAID [19]. For the validation of the questionnaire, was used the Albanian translation of the questionnaire and the Albanian version was translated into English to confirm that we have no changes with the original version of PAID 5.

\subsection{Health Education Program}

All patients in this study before the health education training sessions filled out the self-administered PAID 5 questionnaire and were screened for the levels of $\mathrm{HbAlc}$ in \%. The program consisted of four educational sessions and each session lasted 90 minutes. The first educational session started in the first two weeks after clustering patients into groups. The second educational session took place one month after the first and the last two sessions were offered at one month distance from each other. Educational sessions took place over a period of six months and were provided by trained nursing staff. During this period only the intervention group underwent health education while patients in the control group never participating in any health education activities. Patients were trained for disease management, home management, and lifestyle improvement according to a defined program. The health education in the first session mainly covered general topics connected to diabetes and the importance of routine care, medical checks, and follow-up. In the second session, patients took information about the importance of nutrition in the management of type 2 diabetes. The third session consists of education about the role that lifestyle in type 2 diabetes plays. And the fourth education session consisted of care for long-term diabetes complications and their management. After six months patients in both groups were asked to fill out the PAID 5 questionnaire again.

\subsection{Analytical Methods}

The questionnaire reliability analysis was estimated by the Cronbach alpha coefficient. This coefficient is 0.84 that indicates that the validity of the questionnaire is acceptable $(>0.7)$ and the results should be considered reliable with respect to the determination of emotional distress in diabetic patients. To compare the groups with respect to the interest outcomes, the t-test was used, Mann Whitney $\mathrm{U}$ or Chi-square. Continuous data were presented by average and standard deviation, while categorical data by relative frequencies in percentage. A bivariate correlation was used to evaluate the influence of age and gender on emotional distress changes. The value of $\mathrm{p}<0.05$ is considered significant. To analyze the data was used SPSS version 16 .

\section{Results}

- Table 1 shows the general characteristics of the study population. We had a study population of 200 type 2 diabetes patients, respectively 100 patients in the control and intervention group. Response rate $100 \%$. 
Table 1. Patients' general information by group.

\begin{tabular}{cccc}
\hline Group & Intervention & Control & p value \\
\hline Number of patients & 100 & 100 & \\
Age & $54.03 \pm 9.57$ & $55.82 \pm 7.86$ & 0.393 \\
Gender & & & 0.873 \\
Female & 41 & 47 & \\
Male & 59 & 53 & \\
\hline
\end{tabular}

$\mathrm{t}$ test; $\mathrm{p}<0.05$ accepted as statistically significant.

- Table 2 shows PAID responses in both groups before health education intervention. The results suggest that patients reported a higher percentage in a moderate and somewhat serious problem about items included that describe negative emotions related to diabetes.

- When comparing the groups in the study relative to the mean values of the scores calculated using the PAID 5 assessment tool, there are no statistically significant differences in mean values, in the total value of PAID 5 as well in the mean values of each question. Participants report the highest means relating to fear about living with diabetes, in particular, worrying about the future and the possibility of serious complications and coping with complications related to diabetes (Table 3 ).

- Even when the groups in the study are compared according to the percentage of answers according to each question before the health education intervention, there are no significant differences for each of the questions included in PAID 5 (Table 4).

- When comparing the mean values of HbA1c at the end of the study by study groups, it results that in the intervention group $\mathrm{HbA} 1 \mathrm{c}$ mean is significantly lower than in the control group $(6.2 \%$ vs. $6.8 \%, \mathrm{p}=0.001)$. Comparison of responses to questionnaire PAID 5 at end of the study by groups showed statistically significant differences (Table 5). As show this table, at the end of the study, the group undergoing training had a higher percentage of individuals who already consider the fear to live with diabetes a minor or no problem. The same situation appears even the fact of being depressed; fear of complications in the future as a result of diabetes and that diabetes gets more physical and mental energy. In all questions, model change is significant in the intervention group undergoing education, whereas in the control group the pattern of patient responses is the same in both cases before and after the study.

- Figure 1 shows the levels of PAID 5 scores and HbA1c\% before and after the educational health intervention in both groups. The comparative graph 1 shows that before the interventions the PAID 5 score was almost the same in both groups. After the health intervention, the PAID 5 score levels in the intervention group were lessened, while the control group was almost unchanged. As suggested by Graph 1, HbA1c\% levels in the intervention group 
Table 2. PAID 5 responses in both groups before health education intervention.

\begin{tabular}{lccccc}
\hline \multicolumn{1}{c}{ Questions PAID 5 } & $\begin{array}{c}\text { Not } \\
\text { a problem } \\
\mathrm{N}(\%)\end{array}$ & $\begin{array}{c}\text { Minor } \\
\text { problem } \\
\mathrm{N}(\%)\end{array}$ & $\begin{array}{c}\text { Moderate } \\
\text { problem } \\
\mathrm{N}(\%)\end{array}$ & $\begin{array}{c}\text { Somewhat } \\
\text { serious } \\
\text { problem } \\
\mathrm{N}(\%)\end{array}$ & $\begin{array}{c}\text { Serious } \\
\text { problem } \\
\mathrm{N}(\%)\end{array}$ \\
\hline $\begin{array}{l}\text { Feeling scared when you think } \\
\text { about living with diabetes }\end{array}$ & $1(0.5)$ & $15(7.5)$ & $110(55.0)$ & $55(27.5)$ & $19(9.5)$ \\
$\begin{array}{l}\text { Feeling depressed when you think } \\
\text { about living with diabetes }\end{array}$ & - & $31(15.5)$ & $94(47.0)$ & $69(34.5)$ & $6(3.0)$ \\
$\begin{array}{l}\text { Feeling that diabetes is taking up } \\
\text { too much of your mental and } \\
\text { physical energy every day }\end{array}$ & $1(0.5)$ & $29(14.5)$ & $97(48.5)$ & $67(33.5)$ & $6(3.0)$ \\
$\begin{array}{l}\text { Coping with complications of } \\
\text { diabetes }\end{array}$ & - & $23(11.5)$ & $100(50.0)$ & $70(35.0)$ & $7(3.5)$ \\
\hline
\end{tabular}

Table 3. Comparison of means of score PAID 5 responses according to each question included before health education intervention.

\begin{tabular}{lccc}
\hline \multicolumn{1}{c}{ Group } & Intervention & Control & p values $^{*}$ \\
\hline & Mean & \multicolumn{2}{c}{ Mean } \\
\hline $\begin{array}{l}\text { Feeling depressed when you think about living with } \\
\text { diabetes }\end{array}$ & 2.17 & 2.23 & 0.147 \\
$\begin{array}{l}\text { Feeling scared when you think about living with } \\
\text { diabetes }\end{array}$ & 2.46 & 2.3 & 0.707 \\
$\begin{array}{l}\text { Worrying about the future and the possibility of } \\
\text { serious complications }\end{array}$ & 2.48 & 2.35 & 0.251 \\
$\begin{array}{l}\text { Feeling that diabetes is taking up too much of your } \\
\text { mental and physical energy every day }\end{array}$ & 2.25 & 2.23 & 0.861 \\
\begin{tabular}{l} 
Coping with complications of diabetes \\
\hline
\end{tabular} & 2.33 & 2.28 & 0.623 \\
\hline
\end{tabular}

${ }^{*}$ Mann Whitney U test; $\mathrm{p}<0.05$ accepted as statistically significant.

decreased after the educational intervention, while in the control group were the same.

- Results of logistic regression on the effect of education (controlled by gender and age evidenced that there is a positive, relatively strong and significant correlation $(\mathrm{r}=0.321, \mathrm{p}=0.001)$ between the change in the value of the PAID 5 questionnaire (the level of emotional distress associated with diabetes) and the age of the patients. The greater the age of the patient, the greater the change in the PAID 5 values (or, alternatively, the decrease of the emotional distress associated with diabetes). But in terms of the level of emotional distress associated with diabetes and gender, the decrease is statistically more sensitive to females than to males, showing that education has had more effect on women in relation to emotional distress.

\section{Discussion}

The experimental type study included a total of 200 type 2 diabetic patients, 100 in the intervention group and 100 in control, mean age, respectively $54.03 \pm 9.57$ 
Table 4. Comparison of answers for each of the questions included in PAID 5 by groups before health education intervention.

\begin{tabular}{|c|c|c|c|c|c|c|c|}
\hline Questions PAID 5 & Group & $\mathrm{A} 0^{\wedge}(\%)$ & $\mathrm{A} 1 \wedge(\%)$ & $\mathrm{A} 2 \wedge(\%)$ & $\mathrm{A} 3 \wedge(\%)$ & $\mathrm{A} 4 \wedge(\%)$ & $\mathrm{p}^{*}$ value \\
\hline \multirow{2}{*}{$\begin{array}{l}\text { Feeling scared when you think about living } \\
\text { with diabetes }\end{array}$} & Intervention & 1 & 8 & 52 & 28 & 11 & \multirow{2}{*}{0.182} \\
\hline & control & 0 & 7 & 59 & 31 & 3 & \\
\hline \multirow{2}{*}{$\begin{array}{l}\text { Feeling depressed when you think about living } \\
\text { with diabetes }\end{array}$} & Intervention & - & 16 & 46 & 33 & 5 & \multirow{2}{*}{0.412} \\
\hline & control & - & 15 & 48 & 36 & 1 & \\
\hline \multirow{2}{*}{$\begin{array}{l}\text { Worrying about the future and the } \\
\text { possibility of serious complications by groups }\end{array}$} & Intervention & - & 12 & 38 & 40 & 10 & \multirow{2}{*}{0.412} \\
\hline & control & - & 14 & 40 & 43 & 3 & \\
\hline \multirow{2}{*}{$\begin{array}{l}\text { Feeling that diabetes is taking up too much of } \\
\text { your mental and physical energy every day }\end{array}$} & Intervention & 0 & 16 & 47 & 33 & 4 & \multirow{2}{*}{0.720} \\
\hline & control & 1 & 13 & 50 & 34 & 2 & \\
\hline \multirow{2}{*}{ Coping with complications of diabetes } & Intervention & - & 13 & 46 & 36 & 5 & \multirow{2}{*}{0.498} \\
\hline & control & - & 10 & 54 & 34 & 2 & \\
\hline \multirow{2}{*}{ PAID 5 score before health education } & Intervention & & 11.3 & & & & \multirow{2}{*}{0.345} \\
\hline & control & & 11.9 & & & & \\
\hline \multirow{2}{*}{ Levels of $\mathrm{HbA} 1 \mathrm{c} \%$ before health education } & Intervention & & 7.02 & & & & \multirow{2}{*}{0.118} \\
\hline & control & & 6.9 & & & & \\
\hline
\end{tabular}

${ }^{*}$ Chi square; $\mathrm{p}<0.05$ accepted as statistically significant; $\wedge$ five possible answers with value from 0 to 4 , with 0 representing "no problem" and 4 "a serious problem".

Table 5. Comparison of answers for each of the questions included in PAID 5 by groups after health education intervention

\begin{tabular}{|c|c|c|c|c|c|c|c|}
\hline Questions PAID 5 & Group & $\mathrm{A} 0^{\wedge}(\%)$ & $\mathrm{A} 1 \wedge(\%)$ & $\mathrm{A} 2 \wedge(\%)$ & $\mathrm{A} 3 \wedge(\%)$ & $\mathrm{A} 4 \wedge(\%)$ & $\mathrm{p}^{*}$ value \\
\hline \multirow{2}{*}{$\begin{array}{l}\text { Feeling scared when you think about } \\
\text { living with diabetes }\end{array}$} & Intervention & 6 & 30 & 45 & 17 & 2 & \multirow{2}{*}{0.001} \\
\hline & control & 0 & 7 & 62 & 28 & 3 & \\
\hline \multirow{2}{*}{$\begin{array}{l}\text { Feeling depressed when you think about } \\
\text { living with diabetes }\end{array}$} & Intervention & 12 & 32 & 31 & 23 & 2 & \multirow{2}{*}{0.001} \\
\hline & control & 0 & 14 & 48 & 37 & 1 & \\
\hline \multirow{2}{*}{$\begin{array}{l}\text { Worrying about the future and the } \\
\text { possibility of serious complications }\end{array}$} & Intervention & - & 56 & 17 & 23 & 4 & \multirow{2}{*}{0.001} \\
\hline & control & - & 17 & 44 & 36 & 3 & \\
\hline \multirow{2}{*}{$\begin{array}{l}\text { Feeling that diabetes is taking up too } \\
\text { much of your mental and physical energy } \\
\text { every day }\end{array}$} & Intervention & 11 & 31 & 38 & 18 & 2 & \multirow{2}{*}{0.001} \\
\hline & control & 0 & 14 & 49 & 34 & 3 & \\
\hline \multirow{2}{*}{ Coping with complications of diabetes } & Intervention & 10 & 28 & 36 & 24 & 2 & \multirow{2}{*}{0.001} \\
\hline & control & 0 & 7 & 55 & 36 & 2 & \\
\hline \multirow{2}{*}{ PAID 5 score after health education } & Intervention & 8.75 & & & & & \multirow{2}{*}{0.001} \\
\hline & control & 11.35 & & & & & \\
\hline \multirow{2}{*}{ Levels of $\mathrm{HbAlc} \%$ after health education } & Intervention & 6.2 & & & & & \multirow{2}{*}{0.001} \\
\hline & control & 6.8 & & & & & \\
\hline
\end{tabular}

${ }^{*}$ Chi square; $\mathrm{p}<0.05$ accepted as statistically significant; $\wedge$ five possible answers with value from 0 to 4 , with 0 representing "no problem" and 4 "a serious problem".

and $55.82 \pm 7.86$ with a lower number of females in the intervention group compared to the control group (41 vs. 47) (Table 1). As suggested a study of gender differences in diabetes risk and outcome are depending on biological and psychosocial factors and psychosocial stress have a greater impact on women in comparison to men [20]. As shown in Table 2, PAID 5 responses in both groups before health education intervention indicated that higher percentages of patients have referred to a moderate problem and somewhat serious problem related to feeling scared and depressed in connection with the thought of living with diabetes. In addition, 97 patients in the study reported that feeling that 


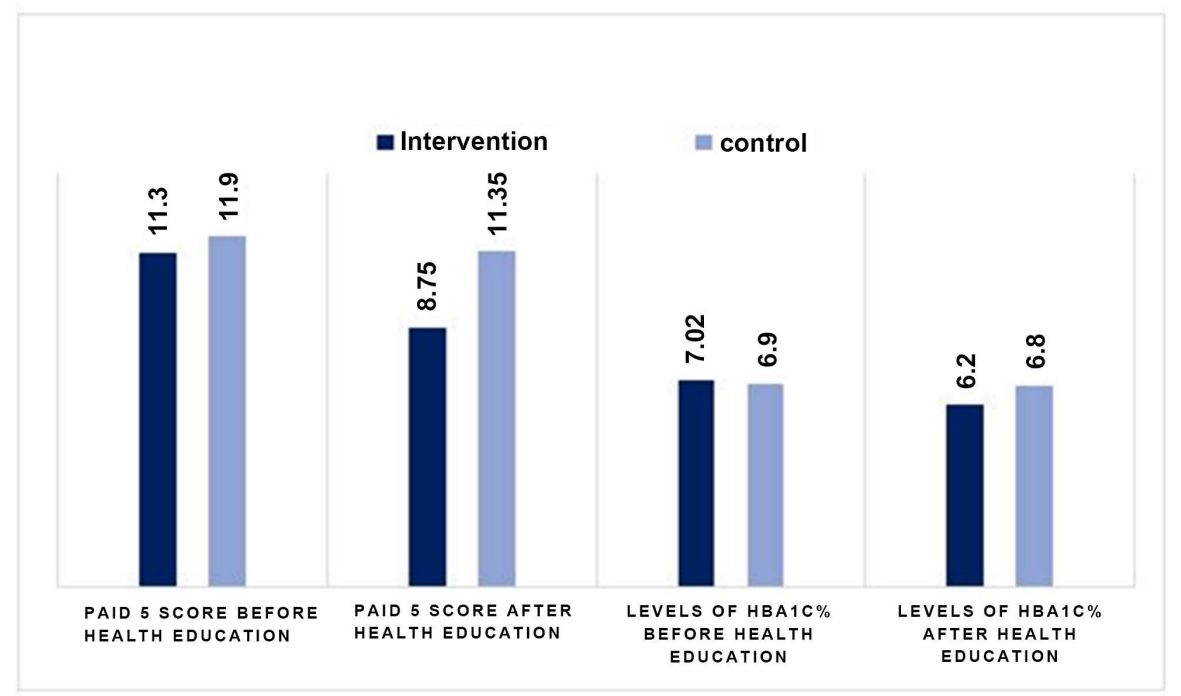

Figure 1. Levels of PAID 5 scores and $\mathrm{HbAlc} \%$ before and after intervention.

diabetes is taking up too much of their mental and physical energy every day is a moderated problem. Half of the patients reported that coping with complications of diabetes is a moderated problem and for $35 \%$ of patients is a somewhat serious problem. Referred to a study, people diagnosed with type 2 diabetes do not have difficulties or problems related to disease in the first years of diagnosis. The problems related mainly to the treatment. This also influences the psychological condition of people diagnosed with diabetes by increasing anxiety and self-care difficulties [21]. Our study does not take into account the time of diagnosis of people with diabetes included in the study and their emotional distress, so it remains a suggestion for future studies. Comparison of means of score PAID 5 responses according to each question included before health education intervention. Table 3 shows that the mean scores have no significant changes in both groups and presented no statistical differences, $\mathrm{p}>0.05$, while Table 4 shows the comparison of answers for each of the questions included in PAID 5 by groups before health education intervention. As seen from this table there are no statistically significant differences in both groups (intervention and control group), $\mathrm{p}>0.05$. PAID 5 scores before health education in intervention and control group were respectively 11.3 and $11.9, \mathrm{p}=0.345$. Referring to the results, the emotional distress in the patients involved in the study in both groups is high since for the PAID 5, a total score of $\geq 8$ indicates possible diabetes-related emotional distress [17]. A study has found that emotional distress related or not to diabetes has a negative impact in self-management of diabetes and reduces the ability of patients to adopt self-management behaviors [22].

As indicated in Table 4, levels of HbA1c\% before health education in intervention and control group were respectively 7.02 and $6.9, p=0.118$. HbAlc can be used as a diagnostic test for diabetes and An HbAlc of 6.5\% is recommended as the cut point for diagnosing diabetes [23]. In addition, a study found that poor glycemic was associated with life modifications adopted as a result of health 
education programs [24]. Table 5 shows the comparison of answers for each of the questions included in PAID 5 by groups after health education intervention. As seen the results of this table the percentage of diabetic patients included in the study that refers to a minor or moderate problem for each variable of PAID 5 is higher in the intervention group, $\mathrm{p}=0.001$. Total PAID 5 score after health education was 8.75 and 11.35 respectively in intervention and control group, $\mathrm{p}=$ 0.001, while total PAID 5 score before health education was 11.3 and 11.9 respectively in intervention and control group (Table 4). The results show that in the intervention group there is a decrease of emotional distress (8.75 vs. 11.3) while in the control group there is no difference at the scoring (11.35 vs. 11.9) but noted a slight increase compared with the scoring before health education (control group did not participate in any educational session). In addition, levels of $\mathrm{HbA} 1 \mathrm{c} \%$ after health education in intervention group were decreased in $6.2, \mathrm{p}$ $=0.001$ compared to the levels of HbA1c\% before health education 7.02 (Table 4 ). While in the control group values of $\mathrm{HbAlc} \%$ were the same as before and after intervention (6.9 vs. 6.8) (Table 4, Table 5 and Graph 1). Results are similar to those of similar studies where the decreasing of emotional distress in diabetic patients was associated with an improvement in glycemic control reflected in the reduction of $\mathrm{HbA} 1 \mathrm{c} \%$ values [25]. In addition, health education in diabetic patients is associated not only with better glycemic control but also in the prevention of complications [10]. As suggested a study, diabetes distress has been associated with worse health outcomes and higher risk for depressive disorder [26]. Another study found that glycemic control and self-care of diabetes is influenced by psychosocial factors [27]. The results of the study on the effect of education (controlled by gender and age evidenced that there is a significant correlation $(\mathrm{r}=0.321, \mathrm{p}=0.001)$ between the change in the value of the PAID 5 questionnaire (the level of emotional distress associated with diabetes) and the age of the patients. The greater the age of the patient, the greater the change in the PAID 5 values. The results are according with a study which found that adult diagnosed with type 2 diabetes at a younger age have higher emotional distress related to diabetes emphasizing the importance of educational programs with a psychosocial focus that has a direct impact on the quality of life of diabetic patients [28]. The results of the study in terms of gender and emotional distress show that the decrease is statistically more sensitive to females than to males, showing that education has had more effect on women in relation to emotional distress. Our results are in contrast with a study which found that female gender and older age were associated with greater odds of diabetes distress [29]. The finding of our study emphasizes even more the role that health education has in reducing emotional distress and better control of glycemia in type 2 diabetic patients. This role has been highlighted in other studies emphasize, even more, the role of health education in reducing emotional distress and better control of glycemia in type 2 diabetes patients with implications in clinical practice by health professionals including nurses [30] [31]. 


\section{Conclusion}

The study found that besides better control of diabetes, additional education of diabetic patients seemed to significantly improve the level of emotional distress due to diabetes in diabetic patients. This improvement in emotional distress has a double value because it affects not only a better control and management of diabetes but also the improvement of the quality of life for diabetic patients and their family members. Diabetes management is a continuous process for both patients and health professionals, so conducting other studies for assessing the impact that health education has on type 2 diabetes self-management is essential.

\section{Conflicts of Interest}

The authors declare no conflicts of interest regarding the publication of this paper.

\section{References}

[1] World Health Organization (2016) Global Report on Diabetes. ISBN 978924 1565257.

http://apps.who.int/iris/bitstream/handle/10665/204871/9789241565257_eng.pdf;jse ssionid=740B1057C66B622653A3BD9D39257E6C? sequence $=1$

[2] American Diabetes Association (2009) Diagnosis and Classification of Diabetes Mellitus. Diabetes Care, 32, S62-S67. https://doi.org/10.2337/dc09-S062

[3] Bregu, A., Toçi, E., Muja, H., Çanaku, D. and Qirjako, G. (2012) Diabetes Prevalence in Albanian Adult Population. Albanian Medical Journal, 4, 9-14.

[4] https://www.diabetes.co.uk/emotions/

[5] Dennick, K., Sturt, J. and Speight, J. (2017) What Is Diabetes Distress and How Can We Measure It? A Narrative Review and Conceptual Model. Journal of Diabetes and Its Complications, 31, 898-911.

[6] Pouwer, F., Kupper, N. and Adriaanse, M.C. (2010) Does Emotional Stress Cause Type 2 Diabetes Mellitus? A Review from the European Depression in Diabetes (EDID) Research Consortium. Discovery Medicine, 9, 112-118.

[7] Virtanen, M., Ferrie, J.E., Tabak, A.G., Akbaraly, T.N., Vahtera, J., Singh-Manoux, A. and Kivimäki, M. (2014) Psychological Distress and Incidence of Type 2 Diabetes in High-Risk and Low-Risk Populations: The Whitehall II Cohort Study. Diabetes Care, 37, 2091-2097. https://doi.org/10.2337/dc13-2725

[8] Berry, E., Lockhart, S., Davies, M., Lindsay, J.R. and Dempster, M. (2015) Diabetes Distress: Understanding the Hidden Struggles of Living with Diabetes and Exploring Intervention Strategies. Postgraduate Medical Journal, 91, 278-283.

[9] Delahanty, L.M., Grant, R.W., Wittenberg, E., Bosch, J.L., Wexler, D.J., Cagliero, E. and Meigs, J.B. (2007) Association of Diabetes-Related Emotional Distress with Diabetes Treatment in Primary Care Patients with Type 2 Diabetes. Diabetic Medicine, 24, 48-54.

[10] Afridi, M.A. and Khan, M.N. (2003) Role of Health Education in the Management of Diabetes Mellitus. Journal of College of Physicians and Surgeons Pakistan, 13, 558-561.

[11] Aikens, J.E. (2012) Prospective Associations between Emotional Distress and Poor Outcomes in Type 2 Diabetes. Diabetes Care, 35, 2472-2478. 
[12] Makki Awouda, F.O., Elmukashfi, T.A. and Hag Al-Tom, S.A. (2014) Effects of Health Education of Diabetic Patient's Knowledge at Diabetic Health Centers, Khartoum State, Sudan: 2007-2010. Global Journal of Health Science, 6, 221-226. https://doi.org/10.5539/gjhs.v6n2p221

[13] Debono, M. and Cachia, E. (2007) The Impact of Diabetes on Psychological Well-Being and Quality of Life. The Role of Patient Education. Psychology, Health \& Medicine, 12, 545-555.

[14] Ministria e Shendetesise. Paketa bazë e shërbimeve në kujdesin shëndetësor parësor. http://www.shendetesia.gov.al/files/userfiles/Shendeti_Publik/Paketa_e_rishikuar_e miratuar.pdf

[15] FSDKSH (2016) Lista e barnave te rimbursueshme. http://www.fsdksh.com.al/images/2016/Faqe_Kryesore/C_Lista_e_Barnave/Lista_e_ barnave_2016.pdf

[16] Papathanasiou, A., Koutsovasilis, A., Shea, S., Philalithis, A., Papavasiliou, S., Melidonis, A. and Lionis, C. (2014) The Problem Areas in Diabetes (PAID) Scale: Psychometric Evaluation Survey in a Greek Sample with Type 2 Diabetes. Journal of Psychiatric and Mental Health Nursing, 21, 345-353.

[17] https://www.huskyhealthct.org/providers/provider_postings/diabetes/PAID-5.pdf

[18] McGuire, B.E., Morrison, T.G., Hermanns, N., Skovlund, S., Eldrup, E., Gagliardino, J., Kokoszka, A., Matthews, D., Pibernik-Okanović, M., Rodríguez-Saldaña, J., de Wit, M. and Snoek, F.J. (2010) Short-Form Measures of Diabetes-Related Emotional Distress: The Problem Areas in Diabetes Scale (PAID)-5 and PAID-1. Diabetologia, 53, 66-69. https://doi.org/10.1007/s00125-009-1559-5

[19] Lee, E.-H., et al. (2014) Measurement of Diabetes-Related Emotional Distress Using Problem Areas in Diabetes Scale: Psychometric Evaluations Shows That the Short Form Is Better than the Full Form. Health and Quality of Life Outcomes, 12, 142. https://doi.org/10.1186/s12955-014-0142-Z

[20] Kautzky-Willer, A., Harreiter, J. and Pacini, G. (2016) Sex and Gender Differences in Risk, Pathophysiology and Complications of Type 2 Diabetes Mellitus. Endocrine Reviews, 37, 278-316. https://doi.org/10.1210/er.2015-1137

[21] Thoolen, B.J., De Ridder, D.T., Bensing, J.M., Gorter, K.J. and Rutten, G.E. (2006) Psychological Outcomes of Patients with Screen-Detected Type 2 Diabetes. The Influence of Time Since Diagnosis and Treatment Intensity. Diabetes Care, 29, 2257-2262.

[22] Schinckus, L., Dangoisse, F., Van den Broucke, S. and Mikolajczak, M. (2018) When Knowing Is Not Enough: Emotional Distress and Depression Reduce the Positive Effects of Health Literacy on Diabetes Self-Management. Patient Education and Counseling, 101, 324-330. https://doi.org/10.1016/j.pec.2017.08.006

[23] World Health Organization (2011) 2. Glycated Haemoglobin (HbA1c) for the Diagnosis of Diabetes. In: Use of Glycated Haemoglobin $(\mathrm{HbAlc})$ in the Diagnosis of Diabetes Mellitus. Abbreviated Report of a WHO Consultation, World Health Organization, Geneva. https://www.ncbi.nlm.nih.gov/books/NBK304271/

[24] Khattab, M., Khader, Y.S., Al-Khawaldeh, A. and Ajlouni, K. (2010) Factors Associated with Poor Glycemic Control among Patients with Type 2 Diabetes. Journal of Diabetes and Its Complications, 24, 84-89. https://doi.org/10.1016/j.jdiacomp.2008.12.008

[25] Strandberg, R.B., Graue, M., Wentzel-Larsen, T., Peyrot, M. and Rokne, B. (2014) Relationships of Diabetes-Specific Emotional Distress, Depression, Anxiety, and Overall Well-Being with HbA1c in Adult Persons with Type 1 Diabetes. Journal of 
Psychosomatic Research, 77, 174-179.

https://doi.org/10.1016/j.jpsychores.2014.06.015

[26] Kreider, K.E. (2017) Diabetes Distress or Major Depressive Disorder? A Practical Approach to Diagnosing and Treating Psychological Comorbidities of Diabetes. Diabetes Therapy, 8, 1-7. https://doi.org/10.1007/s13300-017-0231-1

[27] Ogbera, A. and Adeyemi-Doro, A. (2011) Emotional Distress Is Associated with Poor Self-Care in Type 2 Diabetes Mellitus. Journal of Diabetes, 3, 348-352. https://doi.org/10.1111/j.1753-0407.2011.00156.x

[28] Wingert, A.N., Johnson, L.N. and Melton, S.T. (2015) Understanding Stress among Adults Diagnosed with Type 2 Diabetes at a Younger Age. The Plaid Journal, 1, 30-38.

[29] Nanayakkara, N., Pease, A., Ranasinha, S., Wischer, N., Andrikopoulos, S., Speight, J., de Courten, B. and Zoungas, S. (2018) Depression and Diabetes Distress in Adults with Type 2 Diabetes: Results from the Australian National Diabetes Audit (ANDA) 2016. Scientific Reports, 8, Article No. 7846.

[30] Wardian, J. and Sun, F. (2014) Factors Associated with Diabetes-Related Distress: Implications for Diabetes Self-Management. Social Work in Health Care, 53, 364-381. https://doi.org/10.1080/00981389.2014.884038

[31] Polikandrioti, M. (2010) The Role of Education in Diabetes Mellitus Type 2 Management. Health Science Journal, 4, 201-220. 